\title{
The Study on the Teaching Model of Sports Clubs in Military Colleges \\ Yan Chen
}

\author{
Army Academy of Amored Forces, Beijing ,China \\ chenyan@126.com
}

Keywords: Military academies; Club; Teaching model; Military sports

\begin{abstract}
The traditional sports teaching model seriously ignores the students 'subjectivity and is difficult to adapt to the development requirements of military sports. The teaching mode of the sports club makes up for the traditional teaching mode neglecting to give play to the students 'subjectivity and creativity, and can stimulate and cultivate the students' interest and hobby in physical exercise, which is conducive to the students 'forming a good habit of adhering to physical exercise. The implementation of the sports club teaching mode must establish a scientific operating mechanism, lift the shackles of traditional ideas, and the departments cooperate with each other to make it effective.
\end{abstract}

\section{Introduction}

In China, the teaching model of sports clubs has been developed steadily in other universities. The advantages of the teaching model of sports clubs are very obvious. However, these advantages must be based on the basic characteristics of students 'free choice of courses, free choice of teachers, and free choice of time. It is this "three autonomy" that is in great contradiction with the teaching system of most local colleges and universities, and it is restricted by the conditions of teachers, venues, etc., which makes it difficult for sports clubs to explore, experiment and carry out teaching models. This is why there are fewer local colleges and universities that use the club model for sports teaching. The practice of modern high-tech local war and non-war emergency operations proves that the physical fitness and health of soldiers are an important part of the overall combat effectiveness of the troops. Under the conditions of extensive application of high technology, the combat effectiveness of the strong physical fitness of military personnel in the fulfilment of mission tasks is still irreplaceable. Military colleges and universities are the cradle for training military professionals. Under the current situation of education transition, military school sports education should also internalize the goal of training students 'lifelong sports consciousness, sports ability, and overall health and work adaptability. Establish the teaching form with the student as the main body, attach importance to the development of individuality, and cultivate the ability of the student to study independently, exercise consciously, think actively, and be brave to innovate. The traditional military sports teaching model obviously can not meet the needs of the current military personnel training. In view of this, this paper tries to draw lessons from the advanced experience of the college sports club teaching model, and discusses the promotion strategy of the military sports club teaching in military colleges and universities, so as to better enrich the form of sports teaching in military colleges and universities and effectively improve the physical fitness and health of military personnel. Train more qualified soldiers for the Party and the country.

\section{Comparison between the Teaching Mode of Sports Club and the Traditional Teaching Mode of Physical Education}

Traditional sports teaching model. The traditional sports teaching model has been used in colleges and universities in our country for many years. It was produced under the previous "examoriented education" system. Its teaching goal is to pay attention to imparting the technical skills of sports and achieve the purpose of enhancing the physical fitness of students. The evaluation of results is mainly based on the technical standards examination. The class is composed of natural classes and classes. The teaching content is mainly based on traditional competitive sports events. 
Most of them are track and field, football volleyball and martial arts, aerobics, etc.. During the classroom teaching process, The arrangement of teaching organization, teaching content, teaching schedule, etc. is dominated by teachers. The teachers lead the course of the entire course. The students listen to the arrangement of the teachers. The teachers teach the students how to learn, and the teaching content is arranged according to a unified syllabus. With the teaching of the technical skills of sports programs as the center, there are few necessary rational knowledge content teaching and the cultivation of scientific fitness methods.

Sports club teaching model. The teaching mode of sports club is established under the guiding ideology of lifelong sports, quality education and health. In order to cultivate students 'interest in sports through sports teaching, cultivate students' lifelong sports awareness, give full play to students 'sports talents, meet students' learning interests, and choose their favorite sports projects according to their own interests and their own strengths. We have chosen sports clubs on our own, teachers on our own, and class hours on our own, breaking the boundaries of natural classes, following the autonomous activities of sports clubs, mastering sports skills and methods, and giving full play to individual sports talents, interests and hobbies. Set a good foundation for lifelong exercise and lifelong health. The initial stage of the development of the sports club teaching model is the extracurricular sports club. That is, the students use the spare time to participate in a certain club activity. It is a good extension and supplement of sports activities in school classes. This form is recognized and participated by many sports-loving students.. Later, gradually developed, in order to build a new sports teaching model for the needs of educational reform, the class began to introduce club teaching, changed the traditional model of the past classroom, integrated modern education concepts into the classroom, and changed the traditional class teaching system in organizational form. The roles of teachers and students are interchanged. The students actively learn. The teachers are only responsible for counseling and inspection. The classroom has obvious characteristics such as flexibility, mobility, and selectivity.

\section{Elements of the Teaching Model of Military Sports Clubs}

The teaching model of the military sports club is a controllable open system, which contains elements such as teaching guiding ideology, teaching goals, teaching organization, curriculum content, evaluation indicators, sports venues and equipment.

The teaching guiding ideology focuses on training students 'sports interest, improving students' military sports ability, and guiding students to establish the lifelong sports consciousness of sports.

The teaching goal fully embodies the student's main position, allowing the student to establish his own goals and make his own evaluation. Students have the "three autonomy" that is, the independent choice of teachers, course content and time. While improving students 'physical fitness level, train students' martial arts spirit, fighting style, teamwork awareness and tough will quality.

Teaching methods are mainly based on students, so teachers are relatively flexible in teaching methods, and can adopt corresponding methods according to different conditions of different students. Teachers play an organizational and guiding role in teaching.

The teaching organization of military sports clubs can be divided into two stages: normal teaching and specialty teaching. In the normal teaching stage, the college has opened various types of military sports courses for students, and in the first grade, it has set up special elective courses for military sports to cultivate students 'interests and hobbies, which is conducive to mobilizing students' consciousness and enthusiasm to participate in physical exercise. In the second grade, we began to select clubs and instructors according to personal interests and aspirations. In the form of teaching clubs, we used two hours of extracurricular activities every afternoon and one afternoon of physical exercise on weekends to teach physical education. Students 'teams should fully guarantee the time for participants to participate in military sports clubs. During the special teaching stage, military sports instructors selected a group of outstanding students as the backbone of sports through the teaching and guidance of military sports clubs for a period of time. These sports cadres can serve as assistants to teachers and help teachers organize and coach sports clubs. Some projects, 
such as basketball, football, and long-distance running, can also set up hospital teams and even school teams to represent the school in foreign competitions and win honors for the school.

According to the actual needs of the military, the content of the course is mainly practical, diversified, and competitive. A variety of military sports(such as military triathlon) competitive sports(such as basketball, football, fighting), leisure sports(such as billiards, chess) and ethnic sports(such as wrestling, Tai Chi, martial arts). According to the different competitive characteristics of each project, regular lectures such as health care knowledge, competition rules and referee rules are conducted to enrich the students 'knowledge.

Evaluation indicators At the beginning of the entry of the student into the club, according to the needs of the project to carry out physical tests, and retain data as a reference for evaluating performance. The evaluation of the students should try to avoid the large differences that may be caused by the differences in gender, height, and physical strength of men and women. The "hard" indicators and "soft" indicators should be combined. The proportion of each indicator can be based on the actual situation of the project. "Hard" indicators include technology, competition, and body. "Soft" indicators include students 'ideological quality, learning attitude, psychological quality, team cooperation, and progress. Students who attend club activities on time and complete the course content are given two extracurricular credits per semester. For athletes who represent the college or university in various levels of competition abroad, consideration may be given to giving cultural points based on the level of the competition and the results achieved.

In order to meet the needs of students for sports venues, facilities and club activities under the teaching model of military sports clubs, sports venues and facilities are required to set up more comprehensive projects, and there are more venues for the same project, and facilities are more complete and standardized. The relevant departments of the college shall fully guarantee the sports venues and equipment required by the military sports clubs.

The above elements are complementary and interrelated. They should be optimized and combined in specific situations to make them scientific, holistic and superior.

\section{Organization of the Teaching Model of Military Sports Clubs}

Establishment of organizational structures.Physical education in military schools is an important part of military education and teaching, and an important aspect of carrying out quality education and personnel training. The sports clubs of military schools are the starting point for the implementation of the Regulations on Sports Work in Military Schools. The leaders of military schools should attach great importance to this work, establish and improve organizational structures and rules and regulations, and set up the principal as the leader. The leading group of school sports clubs composed of the Academic Affairs Office, various departments, and sports teachers should clarify their responsibilities, hold regular meetings, and arrange sports teaching, training, and competition plans to ensure the smooth development of the work. The main members 'responsibilities are: the school leader is responsible for the overall responsibility, the Academic Affairs Office directly leads and coordinates the work of various departments, the school sports teaching and research office specifically manages the allocation of clubs and venue equipment, and the clubs guide the instructors to manage the club students.

Establishment of a team of instructors for professional clubs. The formation of a team of experienced, dedicated, and especially capable of fighting instructors is a prerequisite for the school sports club. The school sports teaching and research office should carefully select and employ instructors from various clubs, strengthen teachers 'moral education, clarify the rules on rewards and penalties, put forward specific requirements, require teachers to consciously accept inspection and supervision, strictly abide by various rules and regulations, and ensure the teaching time and quality.

Formulating the Implementation Program of Teaching and Training for Sports Clubs.The teaching implementation plan of sports clubs is the main basis for guiding the teaching work of sports clubs. It mainly includes curriculum setting, teaching goals, rules of course selection, class organization forms, teaching content time distribution, course assessment and evaluation 
requirements, distribution of the number of clubs and organization of classes. In the implementation of the plan, basic fixed guidance teachers, teaching content, number of students, school hours, school places and assessment methods.

Establish and improve assessment and evaluation system. Students participating in sports club activities inside and outside the course should be combined with the participants participating in sports club activities time, with participating in the sports qualification standard test, and with the issuance of graduation certificate. Students must ensure that they participate in sports training at the club at least once a week, and that they must participate in the attendance records of club sports at least 15 times per semester, and pass the level assessment of knowledge, technology, and skills of corresponding sports projects. Participants in the "Physical and Health Standards" test are qualified every school year. To complete the above tasks, you can obtain a sports certificate, and a qualified certificate can be allowed to graduate.

Do a good job in assessing and evaluating students 'physical exercise. To timely record the performance of students in sports clubs, give awards to students who have achieved good results in sports competitions, and timely register and issue sports certificates to students who have completed related teaching tasks in sports clubs. Therefore, in the process of evaluation, we should highlight the evaluation and evaluation criteria of "heavy process, light results, heavy ability, weak selection, heavy participation, and light screening". Combine the assessment with attendance, progress, interest, and cooperation spirit, combine the evaluation of teachers with the self-assessment of individuals, and make a comprehensive evaluation.

\section{Conclusion}

In order to adapt students 'physical fitness and health to the needs of war under high-tech conditions in the future, military colleges and universities can not rely solely on sports classes with very limited class hours. It is necessary to give full play to the role of extracurricular sports. As a new teaching model, sports club teaching mode not only learned some developed countries abroad, but also combined with our own national conditions, has been promoted and used by most colleges and universities, and is deeply loved by contemporary university staff. Under the guiding principle of quality education and "health first", sports teaching in military colleges and universities should also actively explore and experiment with new teaching models such as sports clubs, and carry out clubs with rich and varied content, taking into account the needs of the military and students. Actively create a relaxed environment and lifelong development platform for students, thus helping students establish the concept of "lifelong sports", help students develop a good habit of loving physical exercise, promote the harmonious development of the mind and body of students, and make them qualified soldiers.

\section{References}

[1] Silva Maicon , Sivieri Kátia, Rossi Elizeu. Effects of a probiotic soy product and physical exercise on formation of pre-neoplastic lesions in rat colons in a short-term model of carcinogenic[J]. Journal of the International Society of Sports Nutrition, 2009, 6(1).

[2] Dimitris Vlachopoulos, Alan R Barker, Craig A Williams et al.. Effect of a program of short bouts of exercise on bone health in adolescents involved in different sports: the PRO-BONE study protocol[J]. BMC Public Health, 2015, 15(1).

[3] Jäger Ralf, Purpura Martin, Kingsley Michael. Phospholipids and sports performance[J]. Journal of the International Society of Sports Nutrition, 2007, 4(1).

[4] Shikare S, Samsi A, Tilve G. Bone imaging in sports medicine.[J]. Journal of Postgraduate Medicine, 1997, 43(3).

[5] Reid Angela, Brady Audrey, Blake Catherine et al.. Randomised controlled trial examining the effect of exercise in people with rheumatoid arthritis taking anti-TNF $\alpha$ therapy medication[J]. BMC Musculoskeletal Disorders, 2011, 12(1). 
[6] Abreu N.P., Bergamaschi C.T., di Marco G.S. et al.. Effect of an isotonic rehydration sports drink and exercise on urolithiasis in rats[J]. Brazilian Journal of Medical and Biological Research, 2005, 38(4).

[7] Domhnall MacAuley. OXFORD HANDBOOK OF SPORT AND EXERCISE MEDICINE[J]. Journal of Sports Science and Medicine, 2007, 6(1).

[8] Melonie Burrows. EXERCISE AND BONE MINERAL ACCRUAL IN CHILDREN AND ADOLESCENTS[J]. Journal of Sports Science and Medicine, 2007, 6(3).

[9] Veronica Montfort-Steiger, Craig A. Williams. CARBOHYDRATE INTAKE CONSIDERATIONS FOR YOUNG ATHLETES[J]. Journal of Sports Science and Medicine, 2007, 6(3). 